REVISTA ANDALUZA DE ANTROPOLOGÍA

NÚMERO 14: IRRUPCIONES FEMINISTAS. PROBLEMÁTICAS EPISTEMOLÓGICAS Y POLÍTICAS. FEMINIST EMERGENCES. EPISTEMOLOGICAL AND POLITICAL ISSUES

MARZO DE 2018

ISSN 2174-6796

[pp. 108-132]

http://dx.doi.org/10.12795/RAA.2018.14.07

\title{
LAS LUCHAS DE LAS CAMPESINAS GALLEGAS: \\ LA SECRETARÍA DAS MULLERES DEL SINDICATO LABREGO GALEGO
}

\section{THE FIGHTS OF GALICIAN'S COUNTRYWOMEN: THE SECRETARÍA DAS MULLERES DO SINDICATO LABREGO GALEGO.}

\section{Rebeca Raso \\ Investigadora}

\section{Resumen.}

La justicia social y política es una de las principales preocupaciones de los movimientos sociales emancipatorios y de la filosofía política. El feminismo, como movimiento teóricopráctico, ha criticado la concepción hegemónica de justicia por no contemplar aspectos de la estructura social que sostienen las injusticias; especialmente, las relacionadas con el sistema sexo-género. Esto ha hecho necesario repensar su propia concepción de justicia para ampliar su alcance y mitigar las injusticias. Este texto recoge la experiencia de autoorganización de las campesinas alrededor de la Secretaría das Mulleres del Sindicato Labrego Galego, que ha venido mostrando la íntima relación entre lo que se entiende por privado y por público que deriva en la emergencia de ese repensar para la transformación social. Una de esas acciones es la campaña por la titularidad compartida de las granjas que refuerzan la idea de la inseparabilidad de los paradigmas distributivos y de reconocimiento para enfrentarse a las injusticias derivadas del sistema sexo-género. Además, esa experiencia viene a confirmar la potencialidad de los movimientos sociales en ese proceso reflexivo-activo para la construcción de sociedades más justas. 
Palabras-clave: Justicia Social; Feminismo; Movimientos Sociales; Sistema Sexo-género; Titularidad Compartida

\begin{abstract}
.
Social and political justice is one of the main concerns of both social emancipatory movements and political philosophy. Feminism, as a theoretical and practical movement, has criticised the hegemonic conception of justice, since it doesn't contemplate the aspects of social structure that sustain injustices, specially those related to the sex-gender system. This has made it necessary to rethink their own conception of justice so as to expand its scope and to mitigate injustices. The experience of self-organization of Galician countrywomen around the Secretaría das Mulleres del Sindicato Labrego Galego has shown the emergency of this reconsideration for social transformation. Their actions and speeches reinforce the idea of the inseparability from distributive paradigms and the recognition to face the injustices derived from the sex-gender system. Furthermore, they prove the potentiality of social movements in this reflective-active process for the construction of fairer societies.
\end{abstract}

Keywords: Social Justice, Feminism, Social Movements, Sex-Gender System.

\title{
1.INTRODUCCIÓN
}

Las injusticias sociales son una preocupación central de los movimientos sociales emancipatorios. Estas organizaciones de la sociedad civil han actuado buscando estrategias para romper con las opresiones que les afligen. Son actores sociales importantes y que están íntimamente relacionados con los procesos de transformación social en los que las mujeres son habitualmente invisibilizadas.

Aunque los movimientos sociales emancipatorios y sus organizaciones sean espacios que han promovido avances hacia sociedades más justas, también se encuentran contradicciones entre sus discursos y prácticas, especialmente con aquellas que tienen que ver con las opresiones derivadas del sistema sexo-género; proceso que tiene mucho que ver con la idea preponderante de justicia social y al que el feminismo ha criticado y hecho propuestas alternativas que han promovido un repensar sobre la propia concepción de justicia. Ese repensar es concretado y experimentado por medios de iniciativas y acciones protagonizadas por las feministas dentro y fuera de los movimientos.

En este escenario, el feminismo, como movimiento teórico-práctico, ha criticado la concepción hegemónica de justicia por no contemplar aspectos de la estructura social que sostienen las injusticias; entre ellas, las relacionadas con el sistema sexo-género. Las feministas insisten en la necesidad de una concepción de la justicia en la que todos los 
miembros de la sociedad estén incluidos. Esto implica que cualquier teoría de la justicia tenga el sistema sexo-género como un eje de la estructura social, en tanto que genera desigualdades e injusticias (Fraser et al.; 1996; Young, 2000). Sus contribuciones han ido más allá de una retórica o un acontecimiento restringido a un momento o lugar, siendo uno de los movimientos más influyentes y uno de los ámbitos contemporáneos más productivos en estudios, investigaciones y propuestas sociales en el panorama internacional; resultado que llega a día de hoy a la imposibilidad de pensar la justicia social sin tener en cuenta a las mujeres, pese a las resistencias. Sin embargo, las experiencias protagonizadas por las feministas y mujeres en el seno de los movimientos sociales continúan siendo infravaloradas tanto por los movimientos como por el campo científico.

Dicho esto, en lo que sigue evidencio el potencial transformador de los movimientos sociales en la lucha por construir sociedades más justas a través de la experiencia de autoorganización de las campesinas gallegas alrededor de la Secretaría das Mulleres del Sindicato Labrego Galego (SLG). La experiencia singular de la Secretaría das Mulleres ha motivado un repensar de la justicia social al poner en evidencia la íntima relación entre lo que se entiende por privado y por público en su praxis contra las injusticias derivadas del sistema sexo-género. Sus iniciativas han puesto de manifiesto la potencialidad de los movimientos sociales en el proceso de transformación social, siendo una experiencia de referencia internacional.

De este modo, hago hincapié sobre la campaña por la titularidad compartida de la explotación agraria. Esta campaña ha sido una de las iniciativas de la Secretaría de las Mujeres del SLG que de manera más clara ha promovido cambios en la percepción de justicia social por la afiliación, sirviendo de referencia a otras organizaciones sociales, tanto dentro del Estado español como fuera de él. La trayectoria de la campaña ha evidenciado las relativas líneas que separan lo público-privado, lo personal-político, que son experimentadas por las campesinas en su cotidianidad; razón por la cual se hizo imprescindible articular aspectos distributivos y de reconocimiento para ser capaces de actuar sobre las injusticias.

Guiado por los paradigmas de la justicia y del feminismo, el diseño metodológico llevado a cabo responde a la necesidad de percibir las especificidades de un contexto sociohistórico para entender las expresiones de las opresiones donde ocurren. Al mismo tiempo, se preocupa por escuchar las voces de las protagonistas de las iniciativas y estrategias que se llevan a cabo en ese contexto. La escucha de los sujetos favorece una mejor comprensión de sus necesidades, las razones, los límites y las oportunidades con las que se enfrentan. De ese modo, la investigación se concreta en el análisis de las iniciativas por medio de una triangulación metodológica utilizando la observación participante, el 
análisis documental y entrevistas semiestructuradas a diferentes personas involucradas en el Sindicato Labrego Galego.

De este modo, el texto se divide en cuatro partes. En la primera argumento sobre el potencial emancipador de los movimientos sociales y su capacidad para intervenir en el escenario político desde del enfoque de oportunidades políticas, siendo fundamental que incorporen las reivindicaciones feministas para ser más coherentes y efectivos en el proceso de construcción de sociedades más justas. En la segunda, trato de poner en evidencia algunas contribuciones del feminismo en torno a la cuestión del reconocimiento y la distribución para la justicia social. En la tercera parte pongo el foco sobre el contexto en el cual se desarrolla la Secretaría das Mulleres del Sindicato Labrego Galego, para en seguida profundizar en un análisis más detenido sobre la Campaña por la titularidad compartida de la explotación agraria. Finalizo con las reflexiones finales.

\section{LOS MOVIMIENTOS SOCIALES: ESPACIO ESTRATÉGICO PARA LA CONSTRUCCIÓN DE SOCIEDADES MÁS JUSTAS.}

Los debates alrededor de la justicia social son una preocupación central para los movimientos sociales emancipatorios. Esta preocupación no está motivada por la curiosidad, sino por la necesidad de los grupos sociales oprimidos de salir de la situación de subalternidad. Esa forma específica de organización social está vinculada con la aparición de la época moderna y con la creación de los Estados-Nación y del capitalismo. Los primeros movimientos sociales con un carácter duradero y estable tienen referencia en el siglo XIX en Europa y Norte América, propagándose por el resto del mundo con diversas formas organizativas, múltiples repertorios y una infinidad de reivindicaciones (Tilly, 2009).

Siguiendo el enfoque de los Procesos Políticos u Oportunidades Políticas ${ }^{1}$, los movimientos sociales son un dinámico e importante actor social, con capacidad para influenciar la agenda política en el escenario internacional y local poniendo en relieve sus diagnósticos $\mathrm{y}$ análisis alternativos, sus producciones y experimentaciones de saberes, propuestas, acciones de creatividad social y política. En definitiva, son agentes transformadores de referencia en los procesos de cambio social, estando implicados en las luchas por la demarcación de los escenarios políticos y por su implicación en la producción de una concepción alternativa de ciudadanía, multiplicando los espacios públicos donde se puede cuestionar y construir nuevos significados frente a las diversas opresiones (Escobar, Alvaréz, Dagnino, 2001). Al mismo tiempo, funcionan como "laboratorio

\footnotetext{
1. Autores como Charles Tilly, Donatela Della Porta y Sidney Tarrow son las referencias del enfoque de los Procesos Político o Oportunidades Políticas, pero también podemos incluir a Arturo Escobar, Sónia Alvaréz, Evelina Dagnino, Breno Bringel, Rosalva Aída Hernández entre tantas otras que siguen esta línea, en lo referente a sus análisis de los movimientos sociales y organizaciones. Este enfoque viene haciendo un esfuerzo por confluir los enfoques más influyentes del campo de la acción colectiva contribuyendo a un abordaje más plural y entendiendo los movimientos sociales como actor social dinámico.
} 
social" al promover espacios de creación y experimentación de prácticas, constituyéndose como un espacio de producción social de la realidad, al elaborar saberes y prácticas que (de)construyen significados, valores, ideas y acciones en un recorrido dialéctico, heterogéneo y no lineal. Así interfieren en el proceso de construcción de identidades individuales y colectivas, una vez que toda esa elaboración es fruto del trabajo cotidiano de personas que analizan, preparan y coordinan acciones, movilizaciones, negocian con las autoridades, producen documentación, discursos y prácticas que interfieren en la propia construcción de identidad de los sujetos sociales y en sus formas de actuar en su día a día, como en la familia y con su comunidad más cercana (Gohn, 2014; Melucci, 1999, Terejina, 2010).

Este espacio intermedio que ocupan los movimientos sociales y sus organizaciones entre los procesos sociopolíticos en su sentido más amplio (del Estado y de las organizaciones transnacionales) y aquellos procesos más individuales y/o comunitarios de la vida cotidiana hacen de ellos, movimientos sociales, un potencial vehículo/canal por el cual se puede permitir la politización de todos los aspectos de la vida. Incluso, abren espacio para la redefinición de las esferas de lo público y de lo privado posibilitando la extensión de la democracia y de la democratización de la cotidianidad, una cuestión fundamental para la existencia de la justicia (Agra, 2002; Young, 2000).

Esa deconstrucción y construcción de significados y prácticas están íntimamente relacionados con los procesos de transformación social, en los que las mujeres son habitualmente invisibilizadas. Este hecho se evidencia en la trayectoria de los movimientos, donde se verifica la difícil relación entre el feminismo y los movimientos ligados a la izquierda (antiesclavista, derecho al voto, socialistas, comunistas, anarquistas, demócratas, etc.), causada por la acción feminista ante la persistencia de estos últimos en reproducir, admitir y tolerar las opresiones, especialmente aquellas derivadas del sistema sexo-género, en lugar de actuar sobre ellas; situación ésta que se muestra como contradictoria para los movimientos emancipatorios.

Esas contradicciones continúan existiendo en el interior de los movimientos y sus organizaciones. Éstas pueden expresarse por medio de la exclusión de los espacios de representación, de la toma de decisiones, la secundarización y despolitización de determinadas problemáticas, la división sexual del trabajo, la falta de respetabilidad y de autoridad, humillaciones, intimidaciones, amenazas o, incluso, la violencia sexual. Tales contradicciones siguen sin pasar desapercibidas una vez que las mujeres y el feminismo actúan, generando campos de conflictos (Álvarez, 2009) ricos en iniciativas y estrategias que buscan eliminar las injusticias y que ya han promovido cambios.

En esa trayectoria tienen especial influencia los debates y acciones del movimiento feminista alrededor de las décadas de 1960-70, cuando éste consigue tener un gran alcance en la opinión pública en diferentes lugares, siendo difícil de ocultar. El movimiento ha 
conseguido poner en el centro de los debates las denuncias que hacían a la idea tradicional de que las mujeres no eran seres políticos y a la retórica básica de libertad, igualdad y democracia (Revolución Francesa, siglo XVIII) que siguen sin extenderse a las mujeres; situaciones éstas que continuaban sin tener una buena receptividad en el ya avanzado siglo XX. Además de evidenciar la continua exclusión de las mujeres del ámbito públicopolítico, el movimiento feminista de ese período introduce una novedad que reside en la crítica a las relaciones de poder en el ámbito privado, reivindicando que la participación de las mujeres debería ir más allá de su inclusión en los ámbitos públicos. En esos debates la crítica feminista cuestiona las separaciones público/privado, público/doméstico, y personal/político, llamando la atención sobre los teóricos políticos en general, y la teoría liberal en particular, que ignoran aspectos fundamentales de la justicia tales como la división sexual del trabajo, las relaciones de poder en la familia y el intervencionismo estatal, que están atravesados por el sistema sexo-género.

Cabe recordar que el feminismo es un movimiento heterogéneo, que busca comprender la realidad para actuar sobre las formas de opresión que someten a las mujeres al dominio masculino, buscando romper con ellas (Young, 2000). Su historia de siglos nos cuenta el continuo rechazo a las formas de opresión y su esfuerzo por revertir o deslocalizar los funcionamientos de las estructuras de dominio que separan y jerarquizan económica, política y socialmente las diferencias anatómicas a partir de su construcción sociohistórica, que se basa en valores que producen y reproducen los individuos (Scott, 2008). Su carácter transformador y emancipador cuestiona las relaciones sociales y las estructuras de poder de la sociedad, desvelando como el sistema sexo-género produce opresiones sobre las personas, en particular sobre las mujeres. Ese sistema es entendido como un mecanismo por el cual la sociedad se organiza y se divide simbólicamente en función de la interpretación de las diferencias entre los sexos y que es experimentada en los cuerpos (Benhabib, et. al.,1990).

Así, el feminismo, como movimiento teórico-práctico, ha dirigido su atención y críticas a la dicotomía público-privado, ocupando un papel central en sus textos (Pateman, 1996) y promoviendo como temas públicos de justicia social los ámbitos más privados y personales como la sexualidad y la reproducción (Young, 2000). Además, como argumenta María Xosé Agra (2016), evidencian que la línea que separa esos dos conceptos es fluctuante y cambiante, así como ocurre con lo político y lo no-político. De esta forma, lo público y lo privado son más bien dos esferas que están íntimamente relacionadas, no siendo posible la existencia de una sin la otra, lo que hace necesario una reconceptualización tanto del espacio público y de la democracia, así como del espacio privado para pensar y actuar hacía la justicia social. Se insiste, por lo tanto, en que la ampliación de la política y los problemas de identidad y de justicia estén interrelacionados, configurando gran parte del debate feminista a finales del siglo XX. 
El resultado de la acción teórica y práctica del movimiento feminista pone de manifiesto la imposibilidad de actuar contra las injusticias sin tener en cuenta a las mujeres y $\sin$ reconocer la existencia de las desigualdades de sexo-género. Así, los movimientos que no tuvieran estos aspectos en cuenta pasan a ser cuestionados como agentes transformadores, dándose el desafío de cambiar los discursos y de promover iniciativas que proporcionasen cambios concretos en la vida de las personas, siendo inevitable repensar las estructuras, los discursos y las acciones cotidianas de la organización y de las personas activistas (Della Porta, 2015; Hernández, 2010). Al mismo tiempo, la búsqueda por construir sociedades más justas y los desafíos impuestos por el contexto neoliberal a finales del siglo XX también han llevado a los movimientos sociales a crear espacios que facilitasen confluencia de luchas, aumentando las oportunidades del movimiento feminista de introducir, articular y dar visibilidad a sus reivindicaciones, articulando aquellas de carácter distributivo con las de reconocimiento. Con esto también se amplían las oportunidades de repensar la concepción de justicia hegemónica en nuestra sociedad.

A continuación, se pone luz sobre esa cuestión a partir de algunas contribuciones feministas que han ganado terreno en los debates más recientes, y sobre las que se debe poner especial atención cuando se busca construir sociedades más justas.

\section{JUSTICIA SOCIAL: EL TERRENO COMÚN ENTRE DISTRIBUCIÓN Y RECONOCIMIENTO.}

En esta trayectoria de luchas y conflictos, la actuación del feminismo, desde diferentes perspectivas, ha sido determinante para provocar cambios en las formas de concebir la justicia, lo público y la política, especialmente en los movimientos emancipatorios. Estos siguen influenciados por la concepción hegemónica de la justicia social que, pese a los cambios, continúa estando presente en sus discursos, análisis, estructuras, y en las prácticas cotidianas de las personas que participan de los mismos, que acaban por reproducir opresiones.

Esa concepción preponderante presenta la justicia como una virtud pública estrictamente vinculada con la ciudadanía y las delimitaciones de lo público-político (Agra, 2016). En este campo prevalece un abordaje de la justicia desde su dimensión social, política y pública que lleva consigo los ideales de imparcialidad y universalidad de lo cívico, de lo público, del individuo y de la ciudadanía. En consecuencia, genera dicotomías como universal-particular, público-privado o razón-sentimientos, que sobreviven con buena salud actualmente. Este ideal establece y normativiza una idea de ciudadanía sobre un sujeto-individuo que trasciende y niega las diferencias, reduce la particularidad y la pluralidad de los sujetos sobre una subjetividad que ejerce hegemonía y normativiza ciertos comportamientos y atributos personales, al mismo tiempo que estigmatiza como desviados a otros. Así, la racionalidad queda reservada al sujeto-individuo hombreblanco, 
heterosexual, mientras que las personas negras, gays, lésbicas, viejas, discapacitadas y mujeres son identificadas y naturalizadas como cuerpos desviados.

En palabras de Iris Marión Young (2000), esta supuesta neutralidad e imparcialidad se concreta en privilegios de un grupo social ${ }^{2}$ dominante, cuya experiencia se convierte en el punto de vista universal y, a su vez, excluye todas las otras voces percibidas como diferentes, transformándolas en alteridad. De esta forma, se justifican las estructuras jerárquicas con que se toman las decisiones. En este mismo sentido, las significaciones y los efectos más cotidianos sobre las experiencias corporales sirven de alimento o de disculpa para acentuar las desigualdades estructurales. Como consecuencia, se establece un conjunto de relaciones comunes entre individuos que responden a los procesos discursivos hegemónicos y/o a sus desiguales posiciones en estructuras tales como la división sexual del trabajo, la heterosexualidad normativa y las relaciones de poder atendiendo a las relaciones de sexo-género, lo que viene a decir que las formas de opresión no se restringen a las acciones de unas pocas personas ni tampoco a los ámbitos entendidos por públicos. En resumen, las opresiones son formas estructurales, son condición social de la injusticia, cuyas causas están imbricadas en normas, hábitos y símbolos de las que no se cuestionan los presupuestos ocultos de las reglas institucionales y de las consecuencias colectivas de seguir estas reglas.

Así, Young entiende la opresión de una forma más plural, con carácter sistémico y estructural amplio, que no se limita a una acción o política determinada y que puede conllevar, o no, la distribución. Se remite a impedimentos impuestos a un grupo social de forma sistemática por el hecho de pertenecer a él, implicando relaciones entre grupos y no la existencia de un grupo opresor correlativo, pero sí de un grupo privilegiado. Además, recoge las discusiones de los movimientos emancipatorios que han reconocido que las diferencias de grupo atraviesan las vidas individuales de una multiplicidad de modos, y que esto puede implicar opresión y privilegio en una misma persona en relación con diferentes aspectos de su vida. En su sentido amplio, "la opresión se refiere a las grandes y profundas injusticias que sufren algunos grupos como consecuencia de presupuestos y reacciones, a menudo inconscientes, de gente que en las interacciones corrientes tienen buenas intenciones, y como consecuencia también de los estereotipos difundidos por los medios de comunicación, de los estereotipos culturales y de los aspectos estructurales de

2. De acuerdo con Young, pertenecer a un grupo social no implica tener consciencia como grupo político y tampoco una identidad común. Sí se refiere a tener atributos producidos por las unidades estructurales de forma que posicione a determinados sujetos de manera similar en la estructura social. De manera general, las personas oprimidas sufren alguna limitación en el desarrollo y ejercicio de sus capacidades y en la expresión de sus necesidades, pensamientos y sentimientos que lleva a afrontar una condición común que las coligan de forma particular haciendo partícipe de un grupo social. Pero participar en un grupo social no exime a la persona de tener actitudes que reproduzcan la opresión relacionada con su grupo social. 
las jerarquías burocráticas y los mecanismos del mercado; en síntesis, como consecuencia de los procesos normales de la vida cotidiana." (Young, 2000:75).

Young sostiene que no puede tener una única definición de opresión dados los diferentes factores y la combinación de factores que dan forma a las diversas opresiones y que hacen posible su interseccionalidad. Frente ese desafío, la filósofa identifica cinco caras o familia de categorías que describen la opresión de cualquier grupo, siendo capaz de poner luz sobre las diferentes formas en que se producen y reproducen las opresiones y la interacción entre ellas. La familia de categorías es la explotación, la marginación, la carencia de poder, el imperialismo cultural y la violencia, que atraviesa las instituciones y las acciones, reacciones e interacciones cotidianas de las personas.

Por consiguiente, las preocupaciones relacionadas con las injusticias sociales deben atender a los aspectos distributivos de la justicia, pero también deben tener en cuenta las estructuras sociales que definen y posicionan a mujeres y hombres, como grupos sociales, en condiciones diferentes, basándose en roles y funciones que les fueron determinadas socialmente (Stolcke, 2004), lo que conlleva cuestionar la separación que se hace entre la justicia distributiva y la del reconocimiento como dos paradigmas o aspectos disociados. La primera se remite a aquellos aspectos mensurables, ocultando e ignorando otros que son enfatizados por la segunda, como pueden ser las oportunidades y la autoestima, que limitan a las personas oprimidas en el desarrollo y ejercicio de sus capacidades y en la expresión de sus necesidades, pensamientos y sentimientos, aspectos que condicionan las medidas distributivas, los procedimientos de toma de decisión, la división del trabajo y los diferentes símbolos y significados culturales (universalidad y normatividad).

Además, valora los aspectos que evidencian las diferentes concepciones de justicia. Es importante tener en cuenta cómo cada una de ellas define el alcance de la justicia; es decir, como éstas entienden lo público, lo privado, lo personal y lo político, una vez que la concepción misma de estos términos forma parte de las causas de las injusticias relacionadas con el sistema sexo-género en particular, críticas que ha suscitado el feminismo a las teorías preponderantes de la justicia sobre cómo y en qué medida incorporan o incluyen a las mujeres en la ciudadanía como campo público-político (Agra, 2016).

Por lo tanto, si las injusticias sociales involucran tanto las cuestiones de distribución como las de reconocimiento (que se mantienen por medio de las estructuras sociales que operan en todos los aspectos de la vida), sus medicinas y acciones también deben incidir en estos puntos. Se pone de relieve la indisociabilidad de estos dos aspectos y la necesidad de integrar ambos dentro de un marco comprensivo para tratar las injusticias sociales en un determinado contexto (Fraser et al., 2011). 
Ahora nos resta poner el foco en cómo las iniciativas feministas han articulado esos aspectos para combatir las injusticias que experimentan en su cotidianidad y qué cambios se perciben. Pero para esto hace falta adentrar en un contexto sociohistórico determinado para entender, por un lado, las expresiones de las opresiones donde ocurren y, por otro, con qué límites y oportunidades juegan los sujetos de las iniciativas. En este texto discutiremos las iniciativas desde la experiencia de la Secretaría das Mulleres del Sindicato Labrego Galego.

\section{EL CONTEXTO DE LA SECRETARÍA DAS MULLERES DEL SINDICATO LABREGO GALEGO}

La trayectoria de la Secretaría das Mulleres del Sindicato Labrego Galego (SLG) se destaca por llevar a cabo iniciativas que buscan combatir las injusticias derivadas del sistema sexo-género. Estas han fomentado un repensar de la justicia social al articular las reivindicaciones relativas a la distribución con las de reconocimiento, poniendo en evidencia la íntima relación entre lo que se entiende por privado y público. Además, se suma el hecho singular de que esta organización del movimiento campesino gallego ha sido liderada por mujeres que se reivindican feministas desde hace más de 28 años (1989-2018).

Esta experiencia que ha dado al SLG un reconocimiento tanto a nivel local, en Galicia, donde reside su afiliación, como a nivel internacional por otras organizaciones en las que participa y colabora, como la Vía Campesina y la Marcha Mundial de las Mujeres; reconocimiento éste difícil de encontrar dentro del campo de los movimientos sociales que sigue marcado por los patrones patriarcales que podemos encontrar en el discurso, la organización y el liderazgo (Desmarais, 2007). Estos patrones, como he dicho anteriormente, insisten en la separación, dicotomización y jerarquización de lo público/privado, público/doméstico y personal/político, que colocan a las mujeres en una posición subalterna con respecto a los hombres, aspectos que conforman la base de las criticas feministas.

La Secretaria das Mulleres se desarrolla dentro del contexto de una organización del movimiento campesino, en el Sindicato Labrego Galego (SLG). Creado en la clandestinidad, el SLG se consolida con la celebración de su primer congreso en 1979, al inicio del llamado período de la transición del Estado español. Es una organización ligada a la tradición socialista-leninista que reivindica la soberanía del pueblo gallego y la autoorganización campesina. Participa activamente de los intensos conflictos políticos de ese territorio que derivan especialmente de la Revolución Verde y de las políticas franquistas. Ejerce un papel significativo en las movilizaciones, organización de actos públicos, de elaboración de denuncias políticas y discursos reivindicativos convirtiéndose en una de las organizaciones de referencia y con mayor número de simpatizantes en el período de su consolidación (Cabana, 2013; Cabana, Lanero, 2009). 
Al igual que la mayor parte de las organizaciones mixtas existentes en Galicia, la Secretaría das Mulleres es creada en $1990^{3}$. Siendo Maite Ferreiro su primera responsable (1990-1992), seguida de Purificación Seoane Albela (1994-2002). En un momento en el que el 30\% de su afiliación eran mujeres, muchas de ellas ocupaban papeles importantes cumpliendo tareas de responsabilidad. Sin embargo, la única que integraba el órgano directivo era Lidia Senra, elegida en el Congreso de 1989 para ocupar el puesto de máxima responsabilidad del Sindicato (1989-2007) (Regal, 2010).

La Secretaría das Mulleres, como espacio específico de mujeres, se formaliza respondiendo, por un lado, a las presiones a nivel internacional y local del movimiento feminista con respecto a la igualdad entre hombres y mujeres, especialmente en el ámbito público. Por otro lado, su creación responde a la necesidad de las campesinas de tener un espacio para, de manera colectiva, debatir sobre las problemáticas a las que se enfrentaban por el hecho de ser mujeres y campesinas, y de buscar estrategias para combatirlas. Estas problemáticas eran frecuentes, pero aparecían como casos aislados y no entraban en las prioridades de la organización, como podría ser el impedimento de votar y ser electa en las Cámaras Agrarias por no ser titular de su granja; dificultades para el usufructo de la propia herencia (que con frecuencia recaía sobre el cónyuge) y la negativa a incluirse o su expulsión del Régimen Especial Agrario de la Seguridad Social (REASS) ${ }^{4}$, sobre la alegación de que su marido ya estaba dado de alta en ese sistema, o porque tenía mayores rendimientos que ella. Además, identificaban problemáticas derivadas de la falta de visibilidad, reconocimiento y la inaplicabilidad de una serie de derechos que ya eran un hecho incuestionable para el colectivo de hombres, como el de disponer de una cuenta bancaria a su nombre. También identificaban desigualdades en condiciones y derechos en comparación con las mujeres del medio urbano, que venían disfrutando de conquistas a una mayor velocidad, como pueden ser los derechos y ayudas con relación a la maternidad, el acceso a la información sobre planificación familiar, a contraconceptivos, al divorcio, al carné de conducir e, incluso, el reconocimiento como trabajadoras, ya que participan de las actividades agroganaderas o silvopastoriles de la granja. Esa serie de problemáticas empiezan a ser puestas en relieve ya en los años 1990, como recoge la cita, extraída de un artículo de la revista feminista galega Andaina, confirmando ser la semilla que generará iniciativas que se enfrenten a esas problemáticas.

3. En ese período asistimos a la creación de secretarías de igualdad, de mujeres, de género, en las más diferentes instituciones y organizaciones sociales, provocada por las presiones del movimiento feminista sobre la idea de la necesidad de crear espacios para promover políticas relacionadas con la igualdad entre hombres y mujeres, de dar visibilidad a las mujeres y de ampliar su participación en los ámbitos públicos-políticos, especialmente.

4. Régimen Especial Agrario de la Seguridad Social (REASS) era el sistema específico de seguridad social al que correspondía aquellas personas que se dedicaban al trabajo en la agricultura y/o ganadería. Ese régimen fue excluido en 2011 por la Ley 28/2011 de 22 de septiembre (BOE del 23), siendo las personas integradas en el Régimen General de la Seguridad Social. 
Nos procesos electorais á Cámaras Agrarias, exixe-se para poder elexer ou ser elexidas a cotización á Seguridade Social Agrária, e como na maioria das explotación as condicións económicas non permiten que coticen os dous, é a muller a que non cotiza; polo tanto quéda-se a muller sen poder exercer ese dereito. $\hat{E}$ dicer, na practica somos traballadoras agrárias, pero oficialmente somos "axuda familiar". Neste terreo poderiamos seguir falando longo e tendido e ver como o divórcio é algo tamén practicamente inaplicábel e asi moitos outros dereitos. (Senra, 1990)

Todos estos análisis y la propia organización de la Secretaría tenían como referencia los debates e iniciativas que promovían el movimiento feminista. De acuerdo con las participantes de la Secretaría, su organización empezó con un grupo reducido de mujeres que tenían inquietudes, siendo este un proceso colectivo que iba tomando forma a medida que profundizaban en los temas e iban concienciándose de la magnitud de la situación. Empezaron haciendo reuniones exclusivas de mujeres en algunas comarcas, realizando análisis de la participación de las mujeres en la organización, promoviendo debates, escribiendo en el periódico del SLG, llamado FOUCE, entre otras acciones. Un proceso reconocido como una conquista por las que participaron desde su inicio, como expresa una de las campesinas que participó de todo el proceso de creación de la Secretaría das Mulleres.

E eu creo que aí fomos quen, que fomos capaces de pasar... de avanzar e de facer que todo iso pois e.. fora.. primeiro que a organización fora consciente deso...que a organización, polo tanto, o tivera dentro do seu ordenes do día, ou das súas tal. E polo tanto ter, espazos totalmente lexitimo e eso.. e con totalmente lexitimidade para bueno, para falar, para propoñer cousas, para tal, ou sea, que se non se podía quedar en o que ven de ali, ou igual mais ben nin vir, ni chegar. Igual era, bueno, un grupo de mulleres ou xa nun grupo que igual tiñas cousas concretas nun sitio se. analizada e resolvía ben e se non alí se iba a quedar. Entón eu creo que ai si pasamos do... un pouco do local a un pouco xa, a un aspecto e... nacional. E si esa institucionalización, por chamarlo así, aunque esas palabras nos soe tan tal... e non nos gusten moito e tal, pero bueno, para nos é positiva. (Entrevista 2, M, 2014)

Pero fue en 1996, con la victoria en el proceso judicial de una mujer que había sido expulsada del REASS, lo que dio pie a la visibilización de las problemáticas femeninas dentro de la organización, legitimando una fuerte campaña para la modificación de la legislación del régimen de seguridad social a nivel estatal que se conquistó en 2003 (España, 2003).

Ganar una acción en la justicia contra una ley discriminatoria del Estado significa un gran logro para la izquierda, lo que contribuye a la legitimación de las reivindicaciones de las mujeres dentro del SLG y de la sociedad como un todo. También hace que el 
Sindicato, en general, sea visto desde fuera como una organización comprometida con la transformación social, fortaleciendo aún más la necesidad de que las injusticias relacionadas con el sexo-género sean incorporadas como una de sus prioridades y no como una cuestión sectorial, ni tampoco como una cuestión reducida al discurso.

Todo esto ocurre en un contexto donde existe un número muy elevado de mujeres titulares de explotaciones en comparación con otros territorios, como puede ser Andalucía, donde hay un predominio de latifundios con una mayor cantidad de ingresos monetarios derivados de esa actividad, lo que conlleva que el trabajo agrario se considere un trabajo masculino. En Galicia, en cambio, predomina el minifundio y una fuerte economía de subsistencia entendida como atrasada, en la cual, siguiendo la lógica del sistema sexo-género, el trabajo del campo era visto como complementario para la economía familiar pudiendo ser realizado por las mujeres, y muchas veces entendido como una prolongación del trabajo doméstico. Mientras, los hombres buscan trabajo fuera, sea en el medio urbano o en el extranjero, que les permite tener mayores ingresos monetarios y un mayor estatus social. Así, el cabeza de la familia continua a ser el hombre, responsable de la mayor parte de los ingresos económicos de la Casa ${ }^{5}$ (Méndez, 1980, ).

Esta situación que reafirma la existencia de una división del trabajo en el interior de las Casas, varía dependiendo de la composición de los miembros que la habitan, según el sexo-género, la edad y los recursos de cada Casa. Los trabajos desarrollados en la Casa son interdependientes entre sí y no tienen un valor estático o una división clara entre lo que es para la Casa y para fuera de ella; es decir, lo que es destinado al consumo interno, doméstico, lo privado y lo que es para el mercado, lo público. Aun así, el sistema sexo-género impera, y los hombres serán habitualmente los responsables de aquellas actividades comerciales que impliquen un mayor intercambio monetario. En general, son actividades de mayor estatus y que conllevan un mayor poder en la toma de decisiones de la Casa y de la comunidad, como la compra-venta de los animales de mayor porte, tierras y la representación de la Casa ante el Estado. Las mujeres están más relegadas a las tareas de la huerta, de los pequeños animales, de los trabajos de cuidado y mantenimiento de la casa-edificio. Son las que venden el excedente en los mercados y las transformadoras de los productos primarios como el pan, las mermeladas y los quesos. En ese contexto, la campaña de la Secretaría das Mulleres por el derecho básico de cotizar al REASS gana

5. Voy a diferenciar el término Casa con letra mayúscula del de casa con letra minúscula, apoyándome en los análisis de Lourdes Méndez (1988), entre otras, para explicar la organización de la vida en el contexto del rural gallego. Con el término Casa, me refiero a la unidad de producción y consumo en la que se incluye la casa-edificio (donde se desarrolla la cohabitación de las personas, generalmente familia) que se suma al restante del terreno que habitualmente está dedicado a la producción de policultivos agrícolas. Esta producción sirve tanto para el consumo interno de la familia como para la venta en el mercado, pudiendo tener mayor o menor peso económico en la economía familiar. Esa variación dependerá de una serie de componentes, como composición de la familia, trabajos fuera de la unidad familiar, migración, etc. 
mucha fuerza con un incremento del número de mujeres que se veían en esa situación de injusticia, al percibir que su trabajo debería tener el mismo valor que el de su marido. Como cuentan las protagonistas, ha sido un trabajo lento que pasó por promover debates, elaborar y realizar intervenciones públicas, crear discursos y desarrollar acciones para dar visibilidad a todas estas cuestiones. Además, les hizo encontrarse con otras problemáticas y dar una mayor profundidad a las cuestiones enfrentadas por las mujeres campesinas, ampliando su intervención en las políticas públicas como la de incorporación agraria y en el plan de mejora. También cuestionan y abren debates sobre la poca participación de las mujeres en los espacios de representación del SLG y analizan las políticas relacionadas con la igualdad entre mujeres y hombres, especialmente en materias como la violencia de género, la maternidad o la salud de las mujeres, entre otras, acompañando de cerca los debates suscitados por el feminismo. Todo este proceso es poco visible en la documentación de la organización y en su prensa interna, como la revista FOUCE, lo que significa que sus acciones no eran lo suficientemente importantes para destacarlas o eran entendidas como algo interno, privado, para la organización. Esta situación provocó un mayor esfuerzo por parte de las campesinas para hacer ver sus problemáticas y para que el SLG las incorporase como preocupaciones de la organización en su conjunto.

\section{CONSOLIDACIÓN DE LA SECRETARÍA Y LÍNEAS DE ACCIÓN DESDE EL FEMINISMO}

Los resultados del trabajo llevado a cabo por la Secretaría se perciben con su consolidación en 2002, con la elección de Isabel Vilalba como su nueva representante, y con las noticias sobre las conquistas derivadas de esos más de diez años de acción. Se observa un aumento del número de grupos de mujeres en las comarcas; una intensificación de la participación de las mujeres en las actividades de la organización y en puestos de responsabilidad que influyen sobre su mayor visibilidad; además, se inicia la participación de la Secretaría en espacios como la Marcha Mundial de las Mujeres y la Vía Campesina. La creación de una sección específica para las mujeres en FOUCE, en 2004, marca también una diferencia con respecto a la visibilidad de las campesinas gallegas. Gracias a este espacio, se pueden verificar con mayor claridad sus líneas estratégicas de acción, su discurso sobre las injusticias del sexo-género en el contexto del rural gallego y cómo algunas de sus preocupaciones pasan a ocupar un mayor espacio en las noticias que difunde la organización.

A partir de este período las estrategias de acción y de reivindicaciones de la Secretaría tienen dos líneas principales: una de cara al Estado y las instituciones públicas y privadas, en la que se incluyen todas las campañas reivindicativas por los derechos y acciones dirigidas a las administraciones públicas, las articulaciones con otras organizaciones y la visibilizacióm de las especificidades de las campesinas dentro del movimiento feminista 
y del campesino. La otra línea es interna, poniendo el foco en la praxis del SLG, que implica tanto la estructura sindical como el hacer cotidiano de sus activistas. Esta línea incluiría el trabajo de base, campañas de difusión de los discursos y de las reivindicaciones, promoción y autoorganización de grupos de mujeres en las comarcas, modificación de la dinámica y de la estructura sindical que sostiene y reproduce desigualdades de sexogénero.

Ambas líneas estratégicas se concretan en múltiples acciones o iniciativas que son elaboradas y llevadas a cabo por la Secretaría das Mulleres, con mayor o menor visibilidad o impacto dependiendo del momento, del contexto, de las oportunidades, de los recursos existentes y de los sujetos implicados. Éstas pueden ser categorizadas con base en las seis líneas de acción estructurales. Dicha categorización se fundamenta en el tipo de estrategia utilizada y en el público objetivo de sus acciones, pero de ninguna manera son acciones aisladas y únicas, sino todo lo contrario, son interdependientes, estando en constante comunicación y derivando en otras acciones con mayor o menor peso que no se restringen a un único objetivo. Estas son: (1) Actividades específicas para las mujeres, (2) Acciones administrativas y jurídicas contra las violencias institucionales, (3) Adopción de los principios y el discurso de la Soberanía Alimentaria, (4) Las intervenciones en la estructura del SLG, (5) Creación del espacio de dinamización de la Secretaría das Mulleres, y (6) campañas en contra de la violencia machista.

Todas esas acciones están marcadas por los principales debates del movimiento feminista y por los obstáculos con los que se fueron encontrando las mujeres para sacar adelante sus acciones, garantizar sus derechos y el ejercicio de los mismos. Todas ellas también inciden sobre las especificidades del grupo de mujeres campesinas en las que reivindican su reconocimiento como sujeto social y político para así poder acceder a una serie de derechos (sociales, políticos y económicos) de los cuales se veían y se ven excluidas. Ese ser sujeto de derechos implica una resignificación del ser muller labrega (campesina) que está relacionada con el reconocimiento del sujeto mujer, con un modo de vida, con la dignificación de sus actividades y del papel social que ejercen como productoras de alimentos y mantenedoras del rural vivo. A partir de esa identidad se discuten los impedimentos institucionales y políticos sistemáticos que limitan el desarrollo y el ejercicio de las capacidades individuales y colectivas, del autodesarrollo y de la autodeterminación, condiciones necesarias para la existencia de justicia, de acuerdo con Young (2000).

Ese proceso de articulación entre los aspectos de reconocimiento y distribución en sus iniciativas se ve claramente en la campaña por la Titularidad Compartida, una de las más importantes de toda la historia de la Secretaría. Dicha campaña ha funcionado como un paraguas bajo el cual se hace posible incluir y debatir otras reivindicaciones, evidenciando cómo las campesinas gallegas experimentan en su cotidianidad la separación difusa y 
relativa entre público y privado. Por este motivo, destacamos las reivindicaciones en torno a esa iniciativa.

\section{TITULARIDAD COMPARTIDA: EN BUSCA DE LA REDISTRIBUCIÓN Y DEL RECONOCIMIENTO}

La campaña por la titularidad compartida, como el propio nombre indica, reivindicaba la posibilidad de que una explotación agraria tuviera dos personas como sus titulares. Su objetivo consistía en cambiar la legislación del Estado español que solo concedía los derechos y responsabilidades a una única persona de la familia que trabajase en una granja. Para las otras personas, hasta $3^{\circ}$ grado de parentesco, la legislación contemplaba la figura de "ayuda familiar" o "familiar colaborador" que pasó a poder cotizar a la REASS en 2003, pero no tenían los derechos sobre todos los recursos existentes en la granja. En consecuencia, estas personas estaban excluidas de todos los derechos que vienen adjudicados a la titularidad, como pueden ser las ayudas y créditos, la autonomía y el poder en la toma de decisión en la gestión de sus recursos (venta y compra de productos, equipamientos y animales), la sanidad, la educación o la participación en organismos representativos como las Cámaras Agrarias, entre otras. En este contexto, la titularidad compartida, significa compartir los derechos de propiedad de los medios de producción entre dos personas con vínculos afectivos, que trabajan en la granja, asumiendo el derecho a tener la titularidad de la explotación agraria es clave para poder acceder a los recursos económicos derivados de su trabajo y a todos los demás derechos que son concedidos a las personas que consiguen comprobar su actividad productiva.

Además de lo anteriormente dicho, es importante considerar el hecho de que las mujeres (en Galicia y en todo el Estado Español) son mayoritariamente titulares de aquellas explotaciones con una dimensión económica inferior en comparación con la de los hombres, como señalan las estadísticas oficiales y los estudios sobre la estructura agraria (Carreira, Carral, 2014; Solé, Fernández, 2015). Hay que destacar que son justamente aquellas que están siendo caracterizadas como inviables y tienen menor acceso a ayudas y créditos, siguiendo la tendencia internacional en que se estima que solo el $2 \%$ de las mujeres tienen acceso a la tierra y $1 \%$ de las mujeres consiguen acceder a los créditos agrarios (Vivas, 2012).

De acuerdo con las entrevistadas, la figura de "ayuda familiar" puede contemplar tanto a las mujeres como a los hombres. Sin embargo, la realidad es que quien ocupa mayoritariamente esa figura en los registros de la administración son las mujeres. En 2007, cuando hubo una mayor presión, incluso por el poder autonómico para el cambio en la legislación, hablaban de un número superior a 35.000 campesinas gallegas que figuraban como "ayuda familiar" y que podrían acceder a la titularidad de la granja. Una cantidad de mujeres significativa para una de las comunidades autónomas que aún que tenga uno de los mayores porcentajes de titularidad femenina, rondando el 53,73\%, el 
40\% de este número ya pasan de la edad de jubilación (Solé, Fernández, 2015).

Frente a esa situación, la Secretaría argumenta que esa legislación afectaba, por un lado, a la visibilidad de las mujeres como trabajadoras agrarias, una vez que solo el titular era considerado como tal por la administración, teniendo que darse de alta en la REASS y accediendo a los derechos sociales como tal (ayudas para la maternidad, prestaciones, pensión, etc.). Una situación grave ya que el campesinado del Estado español tiene una de las prestaciones más bajas por jubilación y solamente el 5,5\% de las campesinas del Estado conseguían cotizar los 35 años necesarios para obtener el 100\% de la jubilación en 2010 según denuncia en la FOUCE (n² 286, 2011). Por otro, afectaba a la independencia económica de las mujeres, ya que será en nombre del titular de la granja que estarán registrados en el sistema tributario del Estado los ingresos y demás propiedades que se adquieran en la granja. Lo que en la práctica significa que no tenían derechos sobre todo el trabajo que realizaban y las aportaciones financieras que hicieran, convirtiéndose en dependientes económica y políticamente del titular, que en su mayoría son sus cónyuges. Una situación que se torna más evidente cuando hay un cambio en la unidad familiar, como en los casos de separación, viudedad y de herencias. Una de las técnicas entrevistadas ejemplifica la situación de mayor vulnerabilidad en la que se encuentran muchas campesinas, lo que se agrava aún más cuando hay violencia de por medio.

Entón iso, que pasa? Iso pa que a nivel fiscal esa persoa, esa muller, non ten ingresos de cara a Facenda. E cando fai a renda, o sea, que non emites factura. Que quen emite facturas é a persoa titular da explotación. Entón, é a esa persoa a que figura os ingresos. Entón o 100\% dos ingresos de leite, carne, horta, ou o que sexa que se produza están a nome desa persona, dese home. Se hai animales, estes animales están a nome desa persona. Se hai tractores, estes tractores están a nome desa persona. Se hai establo, os establos están a nome desa persona. Quero decir e se hai terra a saber como... entón aí as mulleres están completamente vendidas. En caso de separación ou tal, bueno, igual despois de 30 años de estar traballando... non teñen nada de nada. Nada lles pertence diso que estivo aí. E é mais, nunca tiveron ingresos en 30 anos. Sabes, de cara a oficialidade, de cara a facenda non son donas do seu traballo. (Entrevista 1, M, 2014)

Así, las consecuencias de esa legislación eran y son vividas por las campesinas en su cotidianidad en la medida en que hay una mayor dificultad para acceder a los recursos y de poder gestionarlos. De esa manera, la legislación no solo colabora con la menor autonomía de las mujeres, sino que la sostiene, al impedirles tener y gestionar sus recursos y limitar su acceso a derechos y beneficios, dejándolas en una situación de mayor vulnerabilidad y de dependencia de terceras personas, tanto económica como socialmente. Al no reconocerlas como titulares, sino como "ayuda familiar", la legislación normaliza que se infravalore el trabajo de las mujeres en la economía familiar y en la sociedad como un 
todo, de forma que se deslegitima su papel sociopolítico. En consecuencia, marginaliza y estigmatiza el papel que desarrollan, favorece la explotación de su fuerza de trabajo en la granja y en la casa-edificio. Careciendo de autonomía económica y de legitimidad social, ellas pierden el poder en la toma de decisiones en todos los ámbitos, incluido el de sus propias vidas.

\section{TITULARIDAD COMPARTIDA: LOS LÍMITES ENTRE EL PÚBLICO Y EL PRIVADO}

El cambio en la legislación en 2011 representó otra conquista para las campesinas. Sin embargo, no fue en los términos reivindicados por ellas durante los diferentes momentos de su tramitación. Argumentan que no se tuvieron en cuenta los impedimentos del sistema sexo-género al no incorporar factores que pudieran promover, en la práctica, los cambios deseados. Estos factores son: (1) la no obligatoriedad de la titularidad compartida, siendo necesario el permiso por parte del titular vigente para dar inicio a la solicitud; (2) la alta carga de documentación y burocracia para abrir el proceso de la titularidad compartida (aunque sea menor que en otros procesos); (3) la falta de imposición de plazos a las comunidades autónomas para la habilitación de los registros de titularidad compartida; (4) la falta de información y conocimiento por parte de la administración sobre el propio proceso de tramitación de las solicitudes; (5) la no recuperación de los registros de solicitudes de la titularidad compartida hechos con anterioridad a la legislación estatal como es el caso de Galicia; (6) la falta de una campaña informativa y divulgativa por parte del Estado para que las mujeres supieran que tienen ese derecho; (7) la falta de incentivos para la inscripción de las mujeres en la titularidad compartida y en la Seguridad Social, ya que estas deben darse de alta.

Se suman a esos factores las consecuencias de otras legislaciones y políticas comola reforma de las pensiones y la Política Agrícola Común (PAC), que intervienen negativamente sobre el rendimiento de las granjas familiares, dificultando que más de una persona pueda darse de alta en la Seguridad Social. Cuando se da este caso, mayoritariamente la que renuncia a darse de alta es la mujer.

Todos esos factores influyeron para que la legislación no cumpliese con las expectativas deseadas y con su objetivo de "constituir un factor de cambio de las estructuras agrarias de modo que las mujeres del mundo rural puedan gozar de una igualdad de derechos efectiva con respecto a los hombres" (España, 2011:1). Así los resultados de la Ley de Titularidad Compartida de 2012 (cuando entra en vigor) hasta 2017 son de tan solo 17 solicitudes en Galicia de las 343 en todo el Estado, según los datos oficiales (MAPAMA, 2018). Es importante señalar que estas solicitudes no fueron hechas solo por mujeres, sino también por hombres. A título ilustrativo, la primera solicitud en Galicia fue hecha por un hombre de Ordes afiliado al SLG. 
Las dificultades y omisiones puestas por la ley y sus políticas hacen que las mujeres tengan muchos problemas para acceder a lo que ahora es su derecho. Sin el apoyo regulativo y normativo que proporciona la ley, se hace más complexo para las mujeres proponer un cambio en titularidad de la granja, especialmente aquellas que están en la situación de "ayuda familiar" y que no tienen propiedades en su nombre, por poner un ejemplo. Uno de los motivos destacados por las entrevistadas es que, en la práctica, proponer el cambio en la titularidad puede significar un cambio en la estructura de poder familiar, dado que la titularidad compartida de la granja puede proporcionar a las mujeres los mismos derechos y responsabilidad sobre los recursos derivados de la granja que tienen su marido, lo que también puede significar una mayor capacidad de interferir sobre la toma de decisiones sobre los recursos de la familia al estar en condiciones económicas más igualitarias con respecto a su cónyuge. A esto se suma los intereses sobre la propiedad y el estatus de la familia que los otros miembros como el suegro, suegra, cuñado, etc. pueden ejercer sobre la toma de decisiones con respecto a titularidad de la granja.

De acuerdo con las entrevistadas, las dificultades vividas están relacionadas con los argumentos y actitudes que reciben por parte de aquellas que detienen el poder de decidir se cambia, o no, la titularidad. Estas ponen en cuestión su confianza, lealtad e, incluso, el amor hacía su marido, pudiendo generar otros problemas como la violencia física o el aumento del control (económico y social), demostrando que no están, en la mayor parte de los casos, en igualdad de condiciones dentro de la unidad familiar. Una situación derivada de la posición que ocupan las mujeres en la estructura social que está atravesada por el sistema sexo-género. Esta estructura se concreta en la desigualdad económica y social entre hombres y mujeres, que deja a ellas una menor disposición de recursos (materiales e inmateriales) para abrir una negociación, incluso dentro de su núcleo más íntimo, donde también influyen de manera significativa los vínculos emocionales y afectivos. Así también se verifica como la familia, en especial el matrimonio heterosexual, continúa significando una célula indisoluble y casi incuestionable en la cual sigue habiendo la idea (que antes estaba normativizada) de que hay un responsable que garantiza los ingresos, el hombre, y la mujer cumple la función de esposa, madre y de "ayuda familiar", como determinaba la ley.

Por lo tanto, las dificultades en el acceso a la titularidad compartida no se restringen al derecho legislativo-distributivo, porque sobre la lógica de la distribución también interfieren los aspectos relativos al reconocimiento. Ambos aspectos están atravesados por las relaciones del sistema sexo-género que se da en todos los ámbitos de la vida, sean estos ámbitos entendidos como privados o públicos. Por lo tanto, las políticas públicas y la legislación, como una herramienta del Estado que tiene (en la mayor parte de los casos) el poder y la legitimidad de normativizar y naturalizar determinados comportamientos, conductas y posiciones sociales deben atender tanto a aquellos aspectos relativos a la 
distribución de los recursos, como los relativos al reconocimiento, atendiendo a las relaciones del sistema sexo-género, si realmente pretende promover cambios en la estructura social que mantienen las injusticias.

Por todo esto, la Secretaría ha trabajado el tema de la titularidad compartida acompañada y articulada con otras diversas problemáticas, en especial con la identidad de las mujeres y su contribución sociopolítica y económica. Esa articulación se hacía por medio de la valoración y del reconocimiento del trabajo femenino en la unidad familiar y en la sociedad como un todo, por medio de la resignificación de la identidad de "muller labrega" (campesina), poniéndola al mismo nivel de la identidad de "labregos" (campesino) como sujetos políticos. También han destacado las contribuciones históricas de las mujeres en la defensa del territorio, en la conservación de las semillas o de saberes, y como promotoras de modelos de producción alternativos al industrial. Sobre esto, es importante resaltar que el SLG trae en su propio nombre la reivindicación de la "comunidade labregal campesinado" como sujeto de derechos y como trabajadores. Lo que ha contribuido para que la resignificación de la identidad labrega sea uno de sus pilares de acción de la Secretaría en todas sus iniciativas.

Ha sido con esta identidad colectiva que las mujeres del SLG han construido discursos reivindicativos de sus derechos y necesidades dentro y fuera de la organización, abriendo procesos de transformación social. Por un lado, las mujeres organizadas alrededor de la Secretaría han conseguido introducir sus problemáticas y reivindicaciones, como ocurre con la titularidad compartida, como una cuestión de justicia social. Por consiguiente, el SLG, en su conjunto, debe actuar con respecto a estas cuestiones. Por otro lado, esos discursos han creado oportunidades favorables y dado herramientas para que las mujeres puedan introducir esos debates dentro de su Casa, entendiéndolas como una cuestión de justicia y no una amenaza. Estrategias que han promovido cambios en las condiciones y en el reparto de tareas, en el acceso a derechos y en sus relaciones sociales, favoreciendo su autodesarrollo y autodeterminación.

Esa apertura de oportunidades se verifica tanto en los discursos de las mujeres como de los hombres participantes del SLG. Ambos identifican situaciones de injusticias para con las mujeres tanto en el ámbito familiar como en el jurídico-administrativo, incidiendo especialmente sobre las altas cargas de responsabilidad en los cuidados y el trabajo doméstico que se suman al trabajo en la granja. Situación a la que las protagonistas añaden otros factores que están relacionados con el contexto de precarización de la vida en el medio rural gallego que van a influir de manera más significativa sobre ellas. Hacen hincapié en factores como la falta de servicios y de recursos públicos, especialmente los relacionados con la educación, salud y transporte, afirmando ser elementos fundamentales para una mejor calidad de vida y para la supervivencia de un rural vivo. En consecuencia, esto influye sobre la acentuación de la despoblación, la burocratización 
y sobre el control de la realización de la actividad campesina y el aumento de coste de la vida en las zonas rurales.

\section{REFLEXIONES FINALES}

Como hemos podido ver, la experiencia de la Secretaria das Mulleres del SLG ha promovido cambios significativos en la vida de las campesinas, en particular, pero también en su relación con el grupo hombres. En el proceso de autoorganización, las campesinas percibieron la necesidad de articular en sus reivindicaciones e iniciativas aspectos distributivos y de reconocimiento en el enfrentamiento de las injusticias del sistema sexo-género. Injusticias que son experimentadas en su cotidianidad en diferentes espacios y ámbitos como la familia, la casa-edificio, la granja, el sindicato, la legislación o las políticas públicas. Esto ha alzado luz sobre la fluctuante y relativa línea que separa lo público-privado y lo personal-político en sus vidas, como argumentan las teóricas feministas. Por otro lado, vimos que las iniciativas que no tienen en cuenta las desigualdades derivadas del sistema sexo-género tienen resultados irrisorios, pese a su potencial. Este es el caso de la ley de titularidad compartida de las explotaciones agrarias. En ese contexto, se observa la importancia que ha desempeñado la Secretaría das Mulleres del SLG como agente con capacidad de inferir en la agenda política local e internacional, al conseguir cambios en las esferas legislativas y en los discursos de los gobiernos. Del mismo modo, se verifica su potencial transformador al poner en práctica diversas y diferentes estrategias de lucha que fueron capaces de introducir nuevas prácticas organizativas, de participación política y en las actitudes diarias de los sujetos, dentro y fuera de su organización. Acciones que potencian transformaciones sociales emancipadoras y en las que la pluralidad de sujetos tenga cabida, abriendo espacio para repensar la idea justicia social hegemónica.

Además, su implicación a nivel internacional ha propiciado poner en el centro de los debates de los movimientos sociales la necesidad de debatir y actuar sobre las injusticias del sistema sexo-género, al mismo tiempo que sobre un modelo de producción y consumo, entendiendo como cuestiones inseparables para pensar sobre qué rural vivo queremos. Esto se verifica en los debates sobre la soberanía alimentaria tanto en la Vía Campesina como en la Marcha Mundial de las Mujeres, donde la Secretaría das Mulleres ha sido clave.

A pesar de la apuesta de la Secretaría y del SLG en la articulación de distribución y reconocimiento en sus iniciativas, los resultados son lentos, a lo que se suman el peligro de los retrocesos, siempre presentes, y a las dificultades de la organización para dar continuidad a las propias iniciativas por motivo de la crisis del mundo campesino. Ésta, ha llevado el rural gallego hacia su transformación en un modelo industrial que acentúa todas las desigualdades, afectando, particularmente, a las mujeres como grupo social, 
además de ser totalmente insostenible ecológica y socialmente. Problemática que se ha intensificado en los últimos años teniendo como consecuencias la destrucción de formas de vida, de redes sociales y medios de vida de los pueblos, imposibilitando su soberanía y autodeterminación. 


\section{REFERENCIAS BIBLIOGRÁFICAS}

Agra, Maria X. (2002) “Género y Justicia Social y Política”. En Neus Campillo (Org.). Género, ciudadanía y sujeto político: en torno a las políticas de igualdad. Madrid: Instituto Universitario de Estudios de la Mujer - Universidad Autónoma de Madrid, pp. 11-36.

Agra, Maria X. (2016) ¿Olvidar a Clitemnestra?: sobre justicia e igualdad. Santiago de Compostela: Universidade de Santiago de Compostela.

Álvarez, Sonia E.; Hoermer, Raphael (Orgs.) (2009) Repensar la Política desde América Latina: Cultura, Estado y Movimientos Sociales. América Latina: Facultad de Ciencias Sociales; Universidad Nacional Mayor de San Marcos. Programa Democracia y Transformación Global.

Escobar, Arturo; Álvarez, S.; y Dagnino, E. (2001) Política cultural y cultura política. Una nueva mirada sobre los movimientos sociales latinoamericanos. Bogotá: ICANH, Taurus. Benhabib, Seyla et al. (1990). Teoría feminista y teoría crítica: Ensayo sobre la política de género en las sociedades de capitalismo tardío. Valencia: Edicions Alfons el Magnànim, Institució Valenciana d'Estudis i Investigació.

Cabana I. Ana; Lanero, Daniel (2009) “Movilización social en la Galicia rural del Tardofranquismo (1960-1977)”. En Historia agraria: Revista de agricultura e historia rural n. 48, pp. 111-132.

Cabana I. Ana (2013) La derrota de lo épico. València: Publ. de la Universitat de València. Della Porta, Donatella (2015) Los Movimientos Sociales. Madrid: CIS.

Desmarais A., Aurelie (2007) La vía Campesina: la globalización y el poder del campesinado. Madrid: Editorial Popular.

España (2003) "Ley 27/2003, de 31 de julio, reguladora de la Orden de protección de las víctimas de la violencia doméstica.". España. BOE https://www.boe.es/boe/ dias/2003/08/01/pdfs/A29881-29883.pdf [Consultado el 7 noviembre de 2016].

España(2011)“Ley35/2011, de4deoctubre, sobretitularidad compartida delas explotaciones agrarias”. España BOE http://www.boe.es/diario_boe/txt.php?id=BOE-A-2011-15625. [Consultado el 25 diciembre de 2015].

Fouce (2011) "Contra a violencia machista das pensións e pola co-titularidade". En FOUCE n. 289 Maio - abril, Mulleres, Santiago de Compostela, pp. 20.

Fraser, Nancy (1996) "Redistribución y Reconocimiento: hacía una visión integrada de justícia del género". En Rita Radl Philipp (Org.). Mujeres e institución universitaria en occidente: conocimiento, investigacion y roles de género. Santiago de Compostela: Universidade de Santiago de Compostela. 
Fraser, Nancy et al. (2011) Dilemas de la justicia en el siglo XXI: género y globalización de Nancy Fraser. Palma -Islas Baleares: Edicions UIB.

Gohn, Maria da Glória (2014) "Pluralidade da representação na América Latina." Soc. estado. [online]. vol.29, n.1 pp.73-90. http://www.scielo.br/scielo.php?script=sci_ arttext\&pid=S0102-69922014000100005\&lng=pt\&nrm=iso. [Consultado el 9 de septiembre de 2017].

Hernández C., Rosalva Aída et al. (2010) Etnografías e Historias de resistencia. Mujeres indígenas, procesos organizativos y nuevas identidades políticas. México: Casa Chata.

MAPAMA. Ministerio de Agricultura y Pesca, Alimentación y Medio Ambiente (2018) “Titularidad Compartida en las explotaciones agrarias." http://www.mapama.gob.es/ es/desarrollo-rural/temas/igualdad_genero_y_des_sostenible/titularidad_compartida/ [Consultado el 4 de febrero de 2018].

Méndez, Lourdes (1988) Cousas de Mulleres: Campesinas; poder y vida cotidiana (Lugo 1940-1980) Barcelona: Anthropos.

Melucci, Alberto (1999) Acción colectiva, vida cotidiana y democracia. México: El Colegio de México - Centro de Estudios Sociológicos.

Pateman, Carole. (1996) El contrato sexual. Barcelona: Anthropos - Universidad Autónoma Metropolitana, Iztapalapa, México.

Carreira P., Xoan Carlos; Carral V. Emilio. (2014) O pequeno é grande. A agricultura familiar como alternativa: o caso galego. Santiago de Compostela: Através.

Regal, Tereixa L. (2010) Lidia Senra Rodríguez: A historia dun liderado entrañable. Santiago de Compostela: Laiovento.

Scott, Joan W. (2008) Género e historia. México: Fondo de Cultura Económica Universidad Autónoma de la Ciudad de México.

Senra, Lidia. (1990) “A muller labrega." Andaina: revista do Movemento Feminista Galego v. 20, pp. 18-19.

Soler, Carles; Fernández. Fernando. (2015) Estructura de la propiedad de tierras en España. Concentración y acaparamiento. Bilbao: Fundación Mundubat y Revista Soberanía Alimentaria, Biodiversidad y Culturas.

Stolcke, Verena. (2004) "La mujer es puro cuento: La cultura del género" Revista Estudios Feministas v. 12, n. 2, pp. 77-105.

Terejina, Benjamín M. (2010) La sociedad imaginada: movimientos sociales y cambio cultural en España. Madrid: Editorial Trotta.

Tilly, Charles; Wood, Lesley J. (2009) Los movimientos sociales, 1768-2008: desde sus orígenes a Facebook. Barcelona: Crítica. 
Vivas, Esther. (2012) Soberanía alimentaria, una perspectiva feminista. Esther Vivas. Disponible en: http://esthervivas.com/2012/01/09/soberania-alimentaria-unaperspectiva-feminista/ [Consultado el 22 de enero de 2016]

Young, Iris M. (2000) Trad. Silvina Álvarez. La Justicia y la política de la diferencia. Madrid: Cátedra: Universitat de València : Instituto de la Mujer. 